\title{
Una lectura de la defensa territorial wixarika desde la complejidad ritual
}

\section{A Reading of Wixarika Territorial Defense Strategies from Ritual Complexity}

\section{Regina Lira Larios}

INSTITUTO DE INVESTIGACIONES HISTÓRICAS-UNIVERSIDAD NACIONAL

AUTÓNOMA DE MÉXICO, liraregina@yahoo.com.mx

Se reflexiona sobre la manera en que autoridades y representantes wixaritari se alían o se desvinculan a instituciones de gobierno, organizaciones y colectivos de la sociedad civil, durante los conflictos que afectan los territorios políticos y sagrados. Se analiza este modo en apariencia contradictorio o inconstante a la luz de la organización comunitaria, la historia y la etnografía del ritual, y se propone pensarlo como dispositivo político e instrumento de análisis que crea las condiciones para reconfigurar las relaciones con la sociedad mestiza que se aprende y se transmite en la práctica ritual.

Palabras Clave: huicholes, complejidad ritual, multiplicidad, Estado, territorio.

Amid conflicts that affect their political and ceremonial territories, Wixarika representatives either ally themselves with governmental and non-governmental institutions and collectivities from civil society, or separate themselves from one or more of these groups. This article proposes thinking of this apparently contradictory or inconsistent modality as a series of political devices and instruments of analysis to reflect on relations with mestizo society that are learned and transmitted through ritual practice. This topic is analyzed in light of Wixarika communal organization, history and ritual.

KEYwORDs: Huichols, ritual complexity, multiplicity, Mexican State, territory.

Fecha de recepción: 19 de junio de 2017 / Fecha de aceptación: 14 de mayo de 2018 /Fecha de versión definitiva: 18 de junio de 2018

\footnotetext{
n mi experiencia en la participación en iniciativas para la defensa de los territorios políticos y rituales wixaritari con la comunidad de Tuapurie -o Santa Catarina Cuexcomatitlán-, con organizaciones civiles o instituciones gubernamentales, he experimentado una sensación de desconcierto ante decisiones que son tomadas por las autoridades tradicionales en algunas co-
} 
yunturas, que me han parecido contradictorias, y han puesto al descubierto mis propios "presupuestos sobre lo político" parafraseando a Marcio Goldman (2014). Este artículo surge de la necesidad de reflexionar sobre este efecto desconcertante, retomando otros casos en que las autoridades tradicionales y los líderes de comunidades, ejidos u organizaciones wixaritari se alían a instituciones gubernamentales, organizaciones no gubernamentales, movimientos políticos, o colectivos de la sociedad civil, o se desvinculan de una o de varias de estas instituciones u organizaciones según la coyuntura en cuestión al enfrentar los crecientes conflictos en torno a proyectos mineros, de infraestructura, turismo, u otros, que afectan de manera latente los territorios políticos y rituales wixaritari.

Me propuse repensar en las formas aparentemente contradictorias o inconstantes, variando el instrumento y la escala de análisis. Primero, retomando la organización del sistema de cargos y la creación coyuntural de instancias intercomunitarias, como las que de manera activa han coordinado la defensa de Wirikuta de corporaciones mineras y su percepción desde la prensa; segundo, haciendo un recorrido regresivo sobre la historia de la participación de los pueblos wixaritari en los movimientos sociopolíticos más importantes en la historia nacional; y tercero, a partir de la etnografía de los actos performativos y lingüísticos en los rituales. Estos tres contextos tienen en común el poner en evidencia una recurrencia de "lo contradictorio" y "lo inconstante", que intentaré demostrar no se reducen a lo confuso, ni tampoco a algo que debe ser resuelto.

Estas reflexiones en curso apuntan hacia una manera alterna de entender este modo de hacer política que propongo se aprende y se transmite en la práctica ritual. En primer lugar, al entender "lo político" como un campo de relaciones establecidas a partir de alianzas plurales e inestables que involucran a humanos y no humanos (Sztutman 2013), y crean las condiciones para multiplicar o reconfigurar las relaciones con la sociedad mestiza y el Estado; y, en segundo, al entender "lo contradictorio" y "lo inconstante" como una vía para acercarnos a las estrategias y análisis sociales indígenas que crean alternativas ante los retos contemporáneos (Kirsch 2006). 


\section{LA ALTERNANCIA EN EL SISTEMA DE CARGOS}

En el 2008, la comunidad indígena agraria de Tuapurie, solicitó a su cabecera municipal en Mezquitic, la electrificación de la localidad de Nueva Colonia, sede de los servicios ofrecidos por el Estado y en rápido proceso de urbanización. Cuando el municipio inició las obras para la construcción de pozos, un "cuerpo de coordinación comunitario interno" en alianza con una organización no gubernamental, levantó una demanda ambiental solicitando el estudio de impacto ambiental para analizar los riesgos potenciales generados por la tala de árboles, en especial, en torno a sitios sagrados cercanos. Ante esto, el entonces presidente municipal de Mezquitic declaraba en una entrevista: "yo no los entiendo, para todo tienen pretextos, es muy difícil así trabajar con ellos [...] Antes nadie iba y les preguntaba y, ahora que vamos, tampoco nos va bien [...] Ya tengo miedo a hacerles o proponerles obras: siempre quedo mal haga o no haga las cosas". ${ }^{1}$ Este tipo de discurso elaborado desde las instancias gubernamentales ha fomentado la falsa creencia de que "el indígena" está "en contra del progreso" cuando lo que se exige es que las obras se realicen conforme a la ley y en respeto de las normas ambientales. También ha fomentado la idea de que "los huicholes" o "no se ponen de acuerdo" o "no están bien informados", lo cual pone en evidencia el desconocimiento de los procesos locales en la toma de decisiones.

Las sociedades wixaritari o huicholas que viven entre la costa del Pacífico, los márgenes del río Santiago y el sur de la Sierra Madre Occidental, en comunidades agrarias, ejidos o territorios en disputa, independientes los unos de los otros, comparten un vasto territorio ritual, cuya tenaz defensa se ejerce en la participación en el sistema de cargos. A nivel comunitario, la organización de las comunidades serranas se sustenta en el sistema de cargos que se estructura en torno a tres ramas -la política-civil, la religiosa y la agraria- que se rige bajo el acuerdo de dos instancias, el Consejo de Ancianos -compuesto por especialistas rituales destacados en su desempeño de car-

${ }^{1}$ Entrevista a Ernesto de la Torre, presidente municipal de Mezquitic, Jalisco, "Electrificación opone otra vez a alcalde vs. huicholes" Periódico Público, 22 de julio de 2008, 16. 
gos a lo largo de su vida- y la Asamblea Comunal que convoca a los comuneros entre dos y cuatro veces al ańo donde se discute y se toman acuerdos avalados mediante actas de asamblea. El sistema de cargos abarca las distintas dimensiones político-territoriales, desde la ranchería (kie), que se liga en lo político a una agencia y a la cabecera, y en lo religioso a un templo parental (xiriki), al centro ceremonial (tukipa) y a una red de sitios sagrados. Éste se compone de un número de cargos variable según la rama, designados en función de habilidades personales, compromisos, pactos o herencias personales, familiares o con los ancestros deificados, e implica cumplir con obligaciones rituales tales como las cacerías de venado, los sacrificios de reses y el depósito de ofrendas en sitios sagrados.

La duración en la ocupación de cargos varía según la rama: un año para los político-civiles, tres para los agrarios y cinco para los religiosos. Este sistema de alternancia diferenciada asegura la participación de los miembros de la comunidad -de "dar servicio" a su comunidad, como ellos lo entienden-durante un periodo que no los arruine económicamente dado el altísimo costo que implica ejercer un cargo que no es remunerado. ${ }^{2}$ Cada grupo entrante aprende colectivamente, redefiniendo su estrategia y alianzas según las posibilidades que permite su propia rama. De modo que las relaciones con las organizaciones externas a la comunidad dependen en cierta medida de la rama a la que se pertenezca (la agraria gestiona las relaciones con las instituciones estatales, la civil con las municipales), aunque éstas se discuten colectivamente en las asambleas.

Este complejo sistema de cargos se ha ido adaptando a las nuevas necesidades. Por ejemplo, se han incorporado funciones creadas expresamente para atender necesidades ligadas a los servicios y programas de gobierno en cuestiones de educación, salud, cultura, agricultura, ganadería, etcétera, si bien estas funciones ocupan un papel secundario en la jerarquía de cargos, pues, no cuentan con insignia ritual como la vara de mando de los cargos políticos o la jí-

${ }^{2}$ Los cargos en la rama agraria reciben un sueldo mensual, así como algunos de la rama político-civil, más según lo que me han compartido, el sueldo no cubre ni la mínima parte de la gasolina en el transporte que requieren los múltiples viajes a la cabecera o al interior de la comunidad misma. 
cara de un antepasado de los cargos religiosos. Este sistema se ha ido adaptando a las condiciones particulares de cada comunidad, pero comparte el mismo mecanismo de alternancia en ciclos diferenciados que asegura la distribución asimétrica y dinámica de las relaciones de poder, lo que impide su concentración en una instancia o figura central (Neurath 2011).

Este sistema ha demostrando su flexibilidad en la manera en que ha incorporado nuevas formas intercomunitarias de organización que se enlazan con su base político-religiosa y territorial cuya emergencia se ha dado en coyunturas de conflictos territoriales y con la participación de instituciones gubernamentales. Por ejemplo, el Consejo Supremo Huichol de los setenta del siglo pasado fue creado durante un periodo de fuerte impulso a obras de infraestructura en el Nayar con los programas COPLAMAR y HUICOT, y en los noventa se creó la Unión de Comunidades Indígenas Huicholes de Jalisco (UCIHJ) también en el contexto del desarrollo de obras hidráulicas que detonaron nuevos conflictos territoriales. La formación de ambas organizaciones fue impulsada por el antiguo Instituto Nacional Indigenista (INI), y fueron reapropiadas por las mismas comunidades como plataformas para presentar sus demandas territoriales ante organismos internacionales como la OIT y difundirlas ante otros movimientos indígenas como el EZLN (Durin 2003, 62-66).

Recientemente, dos asociaciones civiles fueron creadas como tentativa para coordinar acciones a nivel regional. La primera, la Unión Wixárika de Centros Ceremoniales de Jalisco, Durango y Nayarit A.C., constituida en el 2006 con el apoyo de la Comisión para el Desarrollo de los Pueblos Indígenas (CDI), compuesta por un presidente, un secretario y un tesorero que se eligen bajo una lógica de representatividad por estado, es decir con representantes de cada uno de los estados con población huichola (aunque Zacatecas no está incluido) y bajo un sistema de elección por votación en el que participan los comuneros que desempeñan los cargos religiosos en los distintos centros ceremoniales huicholes (tukipa). La segunda, el Consejo Regional Wixárika, creado a consecuencia de la organización desencadenada por la defensa de Wirikuta de las corporaciones mineras y debido al descontento de ciertos sectores sobre el involu- 
cramiento de organizaciones no huicholas en los asuntos territoriales tales como la CDI y las organizaciones no gubernamentales. Está conformada por autoridades tradicionales, civiles, religiosas y agrarias, y por ciudadanos de las cinco comunidades serranas (Tuapurie, Wautła, Kuruxi Manuwe, 'Uweni Muyewe y Tateikié), ${ }^{3}$ donde no siempre han figurado representantes de los territorios en Nayarit que aglutinan casi el $50 \%$ de la población huichola según el último censo del INEGI (2010). La coordinación entre ambas organizaciones ha fomentado la participación progresiva en los distintos territorios huicholes, si bien cada una ha emprendido la defensa territorial con sus propios medios y estrategias.

Según el seguimiento de la defensa de Wirikuta en la prensa nacional e internacional que ha reportado este conflicto de modo sistemático, las estrategias de defensa de una y otra organización han parecido contradictorias, y se entiende que mientras la primera participa con instituciones gubernamentales, la segunda suele oponerse a las resoluciones de la primera y actúa en colaboración con organizaciones no estatales. La "contradicción”, en este caso, no radica en un mero antagonismo dado por posiciones ideológicas, sino en la "inconstancia" de estas alianzas que se han reconfigurado en el curso del conflicto.

Por ejemplo, la Unión Wixárika ha mantenido una colaboración cercana con instituciones de gobierno. Para la defensa de Wirikuta apoyó la iniciativa de protección y salvaguarda de la ruta históricocultural y sitios sagrados en la zona de Wirikuta en la Lista de Salvaguarda Urgente de la Convención de Patrimonio Inmaterial de la unesCo y su declaración como "Área Natural Protegida de Competencia de la Federación” con distintas secretarías de estado como Gobernación, Economía, Reforma Agraria, Medio Ambiente, la CDi y la Procuraduría Agraria, que según un comunicado oficial, la administración del entonces presidente Felipe Calderón "reafirmó el com-

\footnotetext{
${ }^{3}$ Respectivamente en español son llamadas Santa Catarina Cuexcomatitlán, San Sebastián Teponahuastlán, Tuxpan de Bolaños, Bancos San Hipólito y San Andrés Cohamiata. Se localizan en el estado de Jalisco a excepción de Bancos que se encuentra en el estado de Durango y una pequeña porción de Santa Catarina se localiza en el estado de Zacatecas.
} 
promiso con los pueblos indígenas, por respetar su autonomía, cultura, tradiciones y sitios sagrados, e impulsar su desarrollo con base en sus valores, que son aporte a la grandeza nacional". ${ }^{4}$ Esta iniciativa fue inmediatamente impugnada por el Consejo Regional a través de una carta dirigida a la UNESCO firmada por algunas autoridades tradicionales que según indicaba la carta, representan "a la mayoría de las comunidades y a los tukipas (centro ceremoniales) del Pueblo Wixárika”, justificando su rechazo con base en la falta de consulta pública y la necesidad de un mecanismo de protección legal más eficiente, no circunscrito a la Convención de Patrimonio Inmaterial. ${ }^{5}$

Por su lado, el Consejo Regional se creó a raíz de este conflicto y se alió a una amplia red de organizaciones sociales formando el Frente en Defensa de Wirikuta Tamatsima Wahaa que llevó a cabo una campańa con un imponente impacto mediático por su capacidad para movilizar a la sociedad civil y establecer alianzas en altos niveles de la esfera política, intelectual y artística. Tras varios ańos de colaboración y de eficaces acciones de movilización, el Consejo Regional se replegó y comunicó públicamente su conformación como organización independiente, instando a la sociedad civil a que "sigan nuestros pasos en nuestra página nueva y sobre todo los rumbos que irá trazando el Pueblo Wixárika por conducto del Consejo Regional por la Defensa de Wirikuta". ${ }^{6}$

Simultáneamente al establecimiento de alianzas con instituciones gubernamentales, organizaciones y colectivos de la sociedad civil, la Unión Wixárika y el Consejo Regional han participado conjuntamente en ruedas de prensa y pronunciamientos enfatizando la "unidad en una sola voz":

4 "Declarará Gobierno a Wirikuta reserva mineral, no otorgará concesiones", Radio Fórmula, mayo 24 del 2012. https://www.radioformula.com.mx/noticias/mexico/20120524/declarara-gobierno-a-wirikuta-reserva-mineral-no-otorgara-concesiones/

${ }^{5}$ Esta iniciativa fue desechada por aparentes inconsistencias en el expediente técnico entregado a la uneSCO, periódico La Jornada, 8 de junio de 2012, 3, http://www.jornada.unam.mx/2012/06/08/cultura/a03n1cul

${ }^{6}$ Publicado en la página oficial del Consejo Regional Wixarika, http://consejoregionalwixarika.org/?p=40 (Fecha de consulta: 10 de agosto 2015).

${ }^{7}$ Pronunciamiento del Consejo Regional Wixárika por la Defensa de Wirikuta, publicado el 10 de agosto del 2015, en http://consejoregionalwixarika.org/?p=40 
El día de hoy precisamente reafirmamos que las comunidades indígenas Wixaritari de: San Sebastián Teponahuaxtlán-Wautia y Tuxpan-Kuruxi Manuwe de los municipios de Mezquitic y Bolańos, Santa Catarina Cuexcomatitlán-Tuapurie municipio de Mezquitic, San Andrés CohamiataTatei Kie municipio de Mezquitic y Bancos de Calítique o Cohamiata tradicionalmente denominado Bancos de San Hipólito-Uweni Muyewe municipio de Mezquital, Guadalupe Ocotán-Xatsitsarie municipio de la Yesca, las primeras tres del estado de Jalisco y las últimas dos del estado de Durango y Nayarit, quienes conformamos el Pueblo Wixárika nos encontramos en una nueva etapa de hermandad, coordinación y fortalecimiento, reconociendo que la unidad es una necesidad para visibilizarnos ante la comunidad nacional e internacional $^{8}$

En este comunicado se cumple una doble finalidad: el informar a la sociedad civil, en tono casi didáctico, que el "Pueblo Wixárika" es diverso y puede también ser uno, si la coyuntura lo requiere. Responde a la necesidad de un público que desconoce las formas de organización nativas y que en buena parte mantiene una concepción idealizada de las comunidades indígenas como culturas armónicas, unidas y solidarias, expectativa anclada en la idea hegemónica naturalista de sociedad que no tiene base en otros pensamientos (Wagner 2013[1991]). Desde mi perspectiva, este discurso sobre la "unidad" es en efecto una "necesidad" que reclama la exposición mediática, pues la idea misma de totalidad resulta problemática en términos indígenas. Esto no es reflejo de conflictos internos ni de una incapacidad para establecer consensos, sino que el modo de hacer política no pone el énfasis en el consenso sino en crear las condiciones para multiplicar las relaciones con los otros, condiciones a su vez dictadas por la alternancia en la ocupación de los cargos en las distintas ramas que componen el sistema. De aquí que cada colectivo o comunidad cree sus propias alianzas que puedan parecernos inconstantes o contradictorias, distintas o semejantes, o dejar a sectores de la "sociedad" wixarika siempre

${ }^{8} 10$ de agosto del 2015, en http://consejoregionalwixarika.org/?p=40 
fuera. Más, este espacio o vacío contribuye a que las redes y alianzas puedan reconfigurarse, aludiendo a las facciones ausentes $y$ ha sido una estrategia exitosa en la historia de la defensa territorial de los wixaritari.

\section{El "Doble JUego" y la inConstancia COMO estrategia}

\section{A LA LUZ DE LA HISTORIA}

Las sociedades wixaritari son consideradas como un pueblo que históricamente han recurrido a la mediación y la diplomacia en sus relaciones con el Estado, y actualmente se le considera como ejemplar en el ejercicio de su autonomía y sus derechos políticos, que desgraciadamente no los exime de la vulnerabilidad latente que afecta a la población indígena en México. En las últimas décadas, la firma de tratados internacionales y las reformas constitucionales han habilitado mecanismos legales que no siempre resultan eficientes en su aplicación, pero que sin embargo son utilizados por algunas comunidades huicholas, especialmente las serranas, como medios para asegurar la protección legal integral de sus territorios políticos y rituales. Esto ha propiciado una diversificación de las estrategias, situando sus demandas en el marco de los discursos universalistas sobre derechos indígenas, medio ambiente y materia agraria: desde la vinculación con otros movimientos sociales indígenas en el fortalecimiento de la autonomía (como con el Congreso Nacional Indígena y el Ejército Zapatista de Liberación Nacional), la colaboración con las organizaciones no gubernamentales en la defensa territorial desde la perspectiva ambiental y agraria (como con Conservación Humana AC y la Asociación Jaliscience de Grupos Indígenas), la denuncia ante organismos y cortes internacionales o la participación en programas del Estado (como el Programa de Certificación de Derechos Comunales o PROCECOM).

$\mathrm{Al}$ actual periodo de recuperación territorial por la vía legal inaugurado desde el cardenismo - no exento de fricciones- le anteceden más de 100 ańos de violencia ininterrumpida durante la cual los territorios que sobrevivieron al virreinato fueron prácticamente desmantelados (Rojas 1992, 164-165, Aldana 1991, 304-306). La par- 
ticipación en los conflictos sociales de este turbulento periodo entre principios del siglo $\mathrm{xx}$ y todo el XIX ha sido interpretada por los historiadores en relación con las condiciones de vulnerabilidad de los territorios por lo que cada comunidad o pueblo vivió periodos más radicales, conservadores o progresistas, según las coyunturas, que no siempre logran dar cuenta del modo en que esta participación se llevó a cabo, de sus estrategias políticas o de los procesos organizativos que ponen en marcha.

Durante la Cristiada en los treinta, y según lo entiende Jean Meyer, "las tres comunidades se dividieron para alcanzar la misma meta: sobrevivir" (Rojas 1992, 262), cuando San Sebastián se unió a los cristeros, Santa Catarina intentó mantenerse neutra y San Andrés se alió con el gobierno. A la Revolución entraron tarde y cuando los "vecinos" (mestizos) se aliaron a Villa, algunos huicholes se declararon carrancistas y legitimaron el nuevo Estado revolucionario, propiciando la emergencia de líderes que alcanzaron formas de concentración de poder, posiblemente sin precedentes (Morris 2015). Esta concentración de poder pudiera explicarse por un proceso de debilitamiento de las estructuras comunitarias afectadas por la implementación tardía de las leyes de desamortización, la entrada de compañías madereras y la eficacia de la política porfirista en quebrantar los modos de designación de autoridades locales. Durante la primera mitad del siglo XIx, los pueblos colindantes a los valles intermontanos padecieron las invasiones de tierras por hacendados y se aliaron a los movimientos armados como el encabezado por Manuel Lozada con "los Pueblos Unidos del Nayarit" -antes de la cooptación definitiva de sus tierras-, mientras que los pueblos huicholes serranos alternaban su posición, ya sea a favor de los lozadistas en alianza con los conservadores de Tepic y los pueblos coras (o náyeri) que se aliaron en masa, o apoyando las acciones militares de los liberales de Jalisco. Por ejemplo, cuando las primeras noticias sobre los alzamientos de los pueblos náyeri a favor del lozadismo se propagan, el jefe político de Colotlán manda llamar a las "autoridades" de los pueblos huicholes de quien dice "han comprometido no mezclarse en semejantes crímenes sin que pueda descansarse en tal confianza por la facilidad con que esta clase de gentes faltan a su 
palabra". ${ }^{9}$ Algo semejante sucedió durante el movimiento independentista, donde algunos huicholes participaron como flecheros con y en contra de las milicias realistas (Muriá 1991).

En el periodo colonial, la diversidad de alianzas y su carácter ambiguo es aún más pronunciado. De hecho, los "pueblos indios" reconocidos tardíamente en las fuentes como "bisoritas" (1621), "guisoles" (1653), "huitzoles" (1673) o "guicholes" (1783), destacan en las fuentes por haber desempeñado un doble papel como milicias al servicio del rey de España, sujetos a la autoridad colonial bajo el mando directo del virrey con el gobierno de frontera de San Luis de Colotlán. Y también como rebeldes aliados a los náyeri insurrectos "dando oculto auxilio en sus alborotos con armas y dinero" (informe de 1790 en Rojas 1992, 100; Ortega 1996, 127), organizados en torno al centro político y religioso del Tonati cora al que diversos grupos de la región entregaban ofrendas y rendían culto al momento del contacto. Esta doble posición resultó exitosa al fungir como mediadores y "lenguas" (o intérpretes) y se benefició de circunstancias particulares (Güereca 2018). Como súbditos del rey, fueron beneficiados por el sistema de regalos que de forma regular les proporcionaba productos como maíz, herramientas para la agricultura, paños, frazadas, tabaco, sombreros, zapatos, almendras de cacao (Powell 1980, 284), además de la exención de tributo, el derecho a portar armas y montar a caballo, a comerciar con sal a pequeña escala, su libre inserción al trabajo de temporal en las minas y haciendas vecinas (Tello 1984, 305; Mota y Escobar 1966, 77) -que además les permitía desplazarse lejos de sus territorios-, pero sobre todo, a ejercer el control interno de sus territorios y la designación política de sus autoridades locales (Shadow 1991, 63). Como rebeldes, mantuvieron las relaciones que les daba acceso a la red de intercambio interétnico por las rutas hacia la costa controladas por grupos coras, que además de incluir los productos de las zonas bajas, los valles y las sierras, se había enriquecido con otros como reses, ovejas, caballos, mulas y armas con el saqueo a las poblaciones mes-

${ }_{9}^{9}$ AHJ, DN-15-858 CON/257, Carta del jefe político de Colotlán, José de Jesús Borrego, 20 de enero 1858 . 
tizas y espańolas (Arias de Saavedra 1899; Ortega 1996, 21-26), además de mantener activa la facción rebelde que de manera latente recordaba al gobierno colonial la posibilidad de la insurrección que afectaría la extracción de plata de las minas más ricas de la Nueva España en Zacatecas (Lira 2003).

En los informes de la administración colonial es frecuente encontrar denuncias emitidas por criollos y mestizos sobre los "nayaritas fronterizos" que describen como "orgullosos, desatentos, malos vecinos" como lo atestigua un informe rendido al virrey Gálvez en 1783:

Con el Gobno. Vitalicio y absoluto, y con el Seguro de no ser residenciados; se ha observado, han procedido con bastante libertad, en la Admnón. de Justicia, tolerando algunos excesos, de los naturales, y a otros acogidos a la Frontera en perjuicio de las Jurisdicciones, inmediatas, y sin la debida satisfacción de las partes agraviadas. [...] Esta Frontera [...] con muchos privilegios, y prerrogativas del fuero militar, y cuantos se abrigan a su Gobno. gozan de las mismas distinciones que los naturales de dicha Frontera (Informes del Coronel Félix Calleja, en Velázquez 1961, 49).

En sus intentos por posicionarse en la región, los franciscanos insistían por su lado en el carácter "áspero" del nayarita:

Se casan y descasan entre sí siempre que les dá gana, no oyen misa y si alguna vez a persuasión del religioso, entran en la Iglesia, no permanecen en ella más tiempo, que el que el sacerdote tarda en ponerse al altar, y quando se vuelve al Pueblo no halla otra persona que la que se la ayuda. Esto como todos los de lo áspero de la Sierra Madre, se conservan en la idolatría, dando culto y hasiendo funciones públicas a sus ídolos (Rojas 1992, 102).

Y también se lamentaban de la labilidad con la que adquirían las nuevas costumbres:

sucede muchas veces entretenidos en sus juegos y llamarlos el religioso para que oigan misa, y responderle que la diga en buena hora, que ellos no la quieren oir aquel dia, y sacarles el religioso por partido que les esperará hasta que acaben el juego, y tenerle hasta medio día esperando. Otras veces 
sucede que teniendo determinado algun baile, que entre ellos es continuo, por lograr para su festejo mańana, van á la celda del ministro á media noche, y con imperio y osadía le mandan levantar á aquella hora para que les diga misa, si quiere que la oigan, porque necesitan toda la mańana para su baile; y todo esto es preciso tolerarlo, porque si el religioso faltara á darles gusto, tuvieran atrevimiento de perderle el respeto y aun de quitarle la vida, pues con mas leve fundamento se la han quitado a muchos ministros (Arlegui 1851, 118).

Es decir que las fuentes coloniales contienen abundantes descripciones que vinculan la sospecha latente de falta de lealtad, lo indómito del carácter nayarita y la labilidad de sus costumbres, como argumentos para justificar su dominación; vínculo que pudiera repensarse en comparación con la "inconstancia del alma salvaje” del indio amazónico que los jesuitas describen en sus crónicas como incapaz para servir y someterse. Eduardo Viveiros de Castro ha replanteado esta inconstancia como un problema epistemológico al que los jesuitas se enfrentaron, a saber, "La vraie croyance suppose une soumission conforme à la règle, et celle-ci suppose l'exercice de la coercition par un souverain" $(1993,385)$ y con ello remite a un tema bien conocido entre los pueblos amazónicos: el del rechazo del Estado (Clastres 1974).

Si bien durante la Colonia este "doble juego" resultó ser una estrategia política exitosa al garantizar el control interno de una parte de sus territorios, existen indicios para pensar que ésta tiene que ver con una forma de organización política que rechaza las formas centralizadas de poder, como se ha reconsiderado en el contexto amazónico (Sztutman 2013). Esto pondría en cuestionamiento la concepción de los grupos del Nayar como "marginales" a los centros políticos mesoamericanos - como lo ha sostenido la arqueología- y apuntaría hacia una revaloración de su papel como agentes creadores de mecanismos para evitar la gravitación hacia los centros de dominación política. De hecho, Federico Navarrete ha sugerido que las dinámicas de concentración y dispersión reconocidas entre los mayas y los toltecas-chichimecas revelan una desconfianza generalizada hacia el poder que no hacía distinciones esenciales entre un 
dominador y otro, e implicaban procesos de fisión étnica y de migración apuntalados en relatos y prácticas rituales que les permitía tanto desvincularse como colaborar con los centros políticos y económicos (Navarrete 2011, 181, 193).

Recurrir a la historia no cumple la finalidad de demostrar ni el origen ni la continuidad de una práctica, sino de repensar nuestra manera de interpretar los datos históricos a la luz de teorías antropológicas contemporáneas. La reflexión sobre los rasgos que caracterizan este modo de hacer política y dan forma a las relaciones con el Estado "y más alla”" a la luz de la historia y la etnografía contemporánea nos lleva a revalorar las estrategias de una sociedad que rechaza la concentración del poder y desafía la autoridad de múltiples maneras al grado de parecer "inconstante".

\section{MULTIPLICIDAD Y REFLEXIVIDAD EN LA PRÁCTICA RITUAL}

La etnografía sobre los rituales comunitarios y familiares que acontecen en los espacios ceremoniales en la comunidad de Santa Catarina Cuexcomatitlán Tuapurie deja ver que las relaciones contradictorias, inconstantes y múltiples que dan forma a las relaciones con el Estado y las organizaciones no indígenas, son parte central del aprendizaje del comportamiento ritual.

Entre los distintos cargos que componen la rama religiosa del complejo sistema de cargos arriba descrito, los jicareros o xikuritamete que desempeñan un cargo en el centro ceremonial comunitario (tukipa) dirigen las actividades rituales ligadas al ciclo agrícola que implican un complejo, costoso y extenuante trabajo, en el que aprenden, entre muchas otras cosas, a ser muchas personas a la vez. Durante varios meses en los que realizan prácticas de austeridad y desvelo, cacerías, peregrinaciones, labores agrícolas, danzas y actos ceremoniales ligados a la recolección de peyote (Lophophora williamsii), la identidad ordinaria de los jicareros se trastoca acumulando otras identidades que se muestran a partir de formas de hacer y de hablar. A su regreso de la peregrinación a Wirikuta, a los jicareros se les llama peyoteros o hikuritamete y se comportan de tal manera que se les describe como "muy locos", hablan un lenguaje 
incomprensible, responden a muchos nombres, de modo que no se sabe bien "quién está hablando". El comportamiento ritual implica distintas modalidades de acción que pueden distinguirse en las secuencias que se suceden una tras otra, o como parte de una misma secuencia en la que una misma persona actúa de modos contradictorios que pueden parecer desconcertantes para los espectadores, sobre todo para los no iniciados. ${ }^{10}$ Esto se acentúa con los juegos rituales y las inversiones de roles entre chamanes y aprendices, entre cargos de la rama política-civil y del centro ceremonial, o entre wixarika y mestizo, y en la alternancia entre actos solemnes y estremecedores que desatan llantos y los espontáneos y ocurrentes que desatan carcajadas. En este contexto, vemos que el dinamismo con el que las identidades de los jicareros se reconfiguran en la ejecución de actos performativos en el espacio ceremonial puede entenderse en relación con el factor desconcertante que es una constante de la dinámica ritual y hace visible el "elemento inestable" en la noción de persona wixarika que Johannes Neurath (2008) ha subrayado en el plano de las relaciones simbólicas. Así, en el ritual, la identidad no sólo siempre es cuestionada y trastocada sino que la autoridad se desafía de múltiples maneras, fijando los límites de la transgresión.

Si entre los jicareros, la identidad ritual múltiple y compleja se alcanza en el curso de los intercambios rituales asimétricos entre una diversidad de personas humanas y no humanas que los lleva a identificarse con una pluralidad de otros, en el canto ritual esta transformación ocurre de manera más compleja. Aquí, el cantador-chamán (mara’akame) también adquiere identidades múltiples -que son tanto acumulables como reversibles- al combinar en una sola imagen modos de ser contradictorios (Houseman y Severi 1994) -es ances-

\footnotetext{
${ }^{10}$ Para darle sentido a esta multiplicidad en el marco de la acción y más allá de un enfoque simbólico, recurrí a una literatura que entiende la acción ritual como una modalidad particular de acción social y la distingue de otras modalidades de interacción tales como el juego, el espectáculo o la interacción ordinaria implican una orientación distinta entre acción y disposición y una relación de valor entre ambos, distintos grados de implicación afectiva y condiciona las posibilidades de innovación según la "caja de herramientas" formulada por Michael Houseman (2012) y la aproximación elaborada por Caroline Humphrey y James Laidlaw (1997).
} 
tro y descendiente, presa y cazador, hombre y mujer, wixarika y mestizo-. Su identidad se trastoca mediante una técnica enunciativa que consiste en un reposicionamiento deíctico sistemático que crea un efecto multiplicador productor de identidades - que no se produce al infinito sino se restringe a una dinámica de fusión/fisión- en el que tampoco se sabe bien quien habla, y sobre la cual se funda su autoridad como mara'akame. De esta complejidad ritual sobre la cual no podemos aquí extendernos, quisiera hacer hincapié en una de las "voces" que se funden en la voz enunciativa. Se trata de lo que he llamado una voz reflexiva que interviene a lo largo de un canto en breves pasajes que se distinguen por sembrar la duda sobre el estatuto de veracidad de lo que se dice, al decirlo. En uno de sus momentos climáticos, esta voz que duda sobre sí misma -si está hablando bien, si está haciendo bien las cosas- da paso a una voz cuya identidad no puede ser enteramente descifrada y produce una "puesta en abismo" en la que "alguien habla de alguien que está hablando". Esta identidad misteriosa produce un hueco o vacío ad infinitum que favorece la repercusión del elemento secreto del proceso chamánico y es una de las características del canto ritual wixarika (Lira 2014). ${ }^{11}$

Si según los evangelizadores la verdadera creencia supone una sumisión conforme a la regla, la reflexividad ritual propone una forma alterna de experimentar la verdad religiosa que no se enfoca en confirmar la existencia de seres sobrenaturales, sino que la pone en duda y también la desafía. Pensarse a sí mismo y su relación con los otros en el ritual implica mirarse desde distintas perspectivas. Tanto el comportamiento como las estrategias lingüísticas rituales ponen de relieve esta actitud reflexiva que sobresale y distingue a las tradiciones rituales y chamánicas amerindias (Severi 2002).

${ }^{11}$ El análisis detallado de las voces que confluyen en la voz enunciativa en un canto, es parte de mi tesis doctoral arriba citada. Incluir pasajes de estas voces en este apartado no esclarecerían el argumento sino lo complicarían puesto que una frase aislada y fuera de su contexto no necesariamente tiene un contenido proposicional explícito y su eficacia reside en la manera en que una voz convive con las otras, la narrativa, la reflexiva, la puesta en abismo, entre otras. La diversidad de voces es uno de los aspectos más complejos y elaborados en el canto, y el modo en que el cantador produce una imagen compleja y plural de sí mismo. 
Por último, la puesta en cuestionamiento de la idea de sociedad como totalidad y "fetiche durkheimiano" que la etnología amazónica y de melanesia ha puesto a discusión (Viveiros de Castro 1993, Wagner 2013, Strathern 1990) cobra sentido en el contexto ritual wixarika donde la idea de totalidad, mencionada anteriormente, resulta problemática y hasta peligrosa. Es parte de la retórica etnográfica plantear que los rituales tienen como finalidad la búsqueda o restablecimiento de equilibrio del cosmos. Sin embargo, este estado armónico de las cosas está lejos de ser el estado ordinario de las cosas, sino por lo contrario es una experiencia que sólo se alcanza de manera efímera con la experiencia ritual. En el canto, esta noción de totalidad se expresa en su devenir, como algo en proceso de maduración o al punto de la completud, que es un estado inestable, que como hemos mostrado en relación con la identidad ritual o la noción de persona, tiende a revertirse o a reconfigurarse. En el patio ritual, esta totalidad como un todo ordenado se hace visible a manera de imágenes. Por ejemplo, al mediodía de los rituales agrícolas cuando se crea colectivamente una imagen a la que se atribuye la identidad de Nuestra Madre Joven Milpa, Tatei Waxa 'iimari, compuesta de elementos heterogéneos como jícaras, flechas, velas, tablas, partes de animales sacrificados y personas, agregados los unos sobre los otros y ordenados a la perfección por unos minutos. Cada uno de los objetos que la componen es el producto de relaciones de intercambio e identificación con una pluralidad de otros, humanos y no humanos. Como una bella sinopsis de un ciclo ritual, esta imagen a la que he dedicado un análisis detallado es lo más cercano a la idea de totalidad, según mi manera de entender el ritual huichol (Lira 2017). Mas esta totalidad es y debe de ser efímera, pues, implica la acumulación de relaciones cuya concentración implica riesgos. Esta experiencia ritual de lo sagrado, según he aprendido, es en términos huicholes, una experiencia potencialmente peligrosa. Como la etnografía del ritual, la organización comunitaria y la historia de las relaciones con el Estado y las organizaciones e instituciones no indígenas nos han mostrado, estas fuerzas acumuladas deben de ser "enfriadas", "dispersas" o "centrífugas" y producir nuevas configuraciones para mantener el flujo del andar wixarika, yeiyari, o "el costumbre". 
Motivada por mi propia experiencia de desconcierto ante lo que he ido entendiendo como un modo alterno de hacer política, me propuse repensar las formas de lo contradictorio o lo inconstante en distintos contextos en tiempo y en espacio. De este procedimiento he llegado a entender lo contradictorio y lo inestable como dispositivos políticos y herramientas de análisis para pensar las relaciones con la sociedad mestiza y crear estrategias y alternativas ante los retos contemporáneos. Lo que ha sido interpretado como un comportamiento político contradictorio e inconstante, visto desde una perspectiva histórica se convierte en una admirable constancia y tenacidad encaminada hacia un mismo fin: la defensa del territorio y el fortalecimiento de la autonomía cuya fuerza radica en la participación en el sistema de cargos. Esta participación que depende de una duración diferenciada y de su alternancia, mantiene el dinamismo del sistema. La posición que una persona ocupe en una configuración dada, ya sea en la rama de cargos civiles agrarios o religiosos, de antemano le implica la gestión y mantenimiento de ciertas relaciones sobre otras, que preexisten a la intencionalidad de los actuantes, y al mismo tiempo abren la posibilidad de reconfigurar colectivamente las estrategias y las alianzas con las instituciones y organizaciones mestizas. Desde la perspectiva del trabajo ritual, la producción de relaciones contradictorias se entiende en su aspecto generativo como multiplicador de relaciones que se analiza no en un plano simbólico, sino a partir de los actos performativos y lingüísticos que engendran la imagen ambigua del ser wixarika: una persona que puede ser muchas personas a la vez, y por ello establece alianzas con distintas personas a la vez. En la ejecución de estos actos prescritos, se transmite la habilidad para pensarse a sí mismo y a los otros desde distintas perspectivas, a cuestionar toda identidad y a desafiar la autoridad en todas sus formas. Más, "tener cualquier posición de poder es un asunto de alto riesgo", como lo ha sugerido Neurath $(2011,124)$, es un planteamiento que debe redimensionarse, aludiendo tanto a la experiencia histórica que ha demostrado los peligros que la concentración de poder puede acarrear, como a la 
experiencia ritual donde la acumulación y concentración de relaciones con humanos y no humanos dada a ver en imágenes, engendra una experiencia de lo sagrado que se experimenta como peligrosa. La ambigüedad, que lo contradictorio o lo inconstante genera, crea las condiciones para que cada parte de este entramado actúe a favor de un todo en estado permanente de reconfiguración.

\section{Agradecimientos}

Este artículo fue elaborado gracias al Programa de Becas Posdoctorales de la UNAM, durante mi estancia de investigación en el Instituto de Investigaciones Históricas. Versiones de éste fueron presentadas en el Congreso de la American Anthropological Association (2015) y el Seminario sobre "Prácticas y teorías políticas de los pueblos indígenas. Una aproximación entre México y Brasil” impartido por el Dr. Spensy Pimentel y organizado por el Posgrado de Estudios Mesoamericanos (2016). Agradezco los comentarios de los participantes en ambos eventos.

\section{BIBLIOGRAFÍA}

Aldana, Mario A. 1991. "El despojo agrario (al finalizar el siglo $\mathrm{XIX)".} \mathrm{En} \mathrm{Lecturas} \mathrm{históricas} \mathrm{del} \mathrm{Norte} \mathrm{de} \mathrm{Jalisco,} \mathrm{comp.} \mathrm{J.M.} \mathrm{Mu-}$ riá. Guadalajara: Gobierno del Estado de Jalisco.

Arias de SaAvedra, Antonio, fray. 1899 [1673]. "Información rendida por el P. Antonio Arias de Saavedra, acerca del estado de la Sierra del Nayarit en el siglo XvII". En Nayarit. Colección de documentos inéditos, históricos y etnográficos de la sierra de este nombre. Alberto Santoscoy. Guadalajara: Gobierno del Estado de Jalisco.

Arlegui, José. 1851 [1737]. Crónica de la P.N.S.P. de Zacatecas. México: Por Cumplido, calle de los Rebeldes, número 2.

Clastres, Pierre. La société contre l'état. París: Les Éditions de Minuit, 1974.

Durin, Séverine. 2003. Sur les routes de la fortune. Commerce à longue distance, endettement et solidarité chez les Wixaritari (Hui- 
chol), Mexique. Tesis de Doctorado en Antropología, Université Paris III.

Goldman, Marcio. 2014. "Da existencia dos bruxos (ou como funciona a antropología). Revista de Antropologia da UFSCar 6(1) (enero/julio): 7-24.

GǘreCa Durán, Raquel. 2018. Caciques, "lenguas" y soldados fronterizos: actores indigenas en la conquista del Nayar (1721-1722). Tesis de Doctorado en Estudios Mesoamericanos, Posgrado de Estudios Mesoamericanos, Universidad Nacional Autónoma de México.

Houseman, Michael. 2012. "Vers un modèle anthropologique de la pratique psychothérapeutique". Le rouge est le noir. Essais sur le rituel, París: Presses Universitaires du Mirail.

Houseman, Michael y Carlo Severi. 1994. Naven ou le donner à voir. Essai d'interprétation rituelle. París: CNRS, Éditions Maison des Sciences de l'Homme.

Humphrey, Caroline y James Laidlaw. 1997. The archetypal actions of ritual. A theory of ritual illustrated by the Jain rite of worship. Oxford: Clarendon Press.

Kirsch, Stuart. 2006. Reverse Anthropology: Indigenous Analysis of Social and Environmental Relations in New Guinea. Stanford: Stanford University Press.

LiRA, Regina. 2003. La organización colonial en la Sierra del Nayar de 1530 a 1722: un espacio pluridimensional. Tesis de Licenciatura en Historia, Universidad Nacional Autónoma de México.

. 2014. L'alliance entre la Mère Maïs et le Frère Aîné Cerf: action, chant et image dans un ritual wixárika du Mexique. Tesis de Doctorado en Antropología Social y Etnología, Écoles des hautes études en sciences sociales,

2017. "Nuestra Madre Milpa Joven: Una imagen de la totalidad efímera en un ritual wixárika", Journal de la Société des Américanistes 103(1): 151-178.

Morris, Nathaniel, 2015. "The World Created Anew": Land, Religion and Revolution in the Gran Nayar Region of Mexico (19101940). Tesis de Doctorado en Historia, Universidad de Oxford. Mota y Escobar, Alonso de la. 1966 [1605]. Descripción geográfica de los reynos de Nueva Galicia, Nueva Vizcaya y Nuevo León. Gua- 
dalajara: Instituto Jaliscience de Antropología e Historia, Instituto Nacional de Antropología e Historia.

Muriá, José María, comp. 1991. Lecturas históricas del Norte de Jalisco. Guadalajara: Gobierno del Estado de Jalisco.

Navarrete, Federico. 2011. "Las dinámicas históricas y culturales de ciclos de concentración y dispersión en las sociedades amerindias". En Los pueblos amerindios más allá del Estado, coord. F. Navarrete y B. Alcántara. México: Universidad Nacional Autónoma de México.

Neurath, Johannes. 2008. "Cacería ritual y sacrificios huicholes: entre depredación y alianza, intercambio e identificación”. Journal de la Société des Américanistes 94(1): 251-283.

.2011. "Ambivalencias del poder y del don en el sistema político ritual wixárika". En Los pueblos amerindios más allá del Estado, coord. F. Navarrete y B. Alcántara. México: Universidad Nacional Autónoma de México.

Ortega, José de. 1996 [1754]. Apostólicos afanes de la Compañía de Jesús en su Provincia de México. México: CEMCA, Instituto $\mathrm{Na}-$ cional Indigenista.

Powell, Philip. 1980. Capitán Mestizo: Miguel Caldera y la frontera norteña. México: Fondo de Cultura Económica.

Rojas, Beatriz. 1992. Los huicholes: Documentos históricos. México: Instituto Nacional Indigenista.

SeverI, Carlo. 2002. "Memory, Reflexivity and Belief. Reflections on the Ritual use of Language". Social Anthropology 10(1): 23-40.

Shadow, Robert. 1991. "Conquista y gobierno español". En Lecturas históricas del Norte de Jalisco, comp. José María Muriá, 43-69. Guadalajara: Gobierno del Estado de Jalisco.

Strathern, Marilyn. 1990. The Gender of the Gift. Los Ángeles: University of California Press.

Sztutman, Renato. 2013. "Metamorfosis do Contra-Estado. Pierre Clastres e as Políticas Amerindias". Ponto Urbe (13): 1-19.

Tello, Antonio. 1984. Crónica Miscelánea de la Sancta Provncia de Xalisco. Libro Segundo. Vol. III. Guadalajara: Gobierno del Estado de Jalisco, Universidad de Guadalajara, Instituto Jaliscience de Antropología e Historia. 
Velázquez, María del Carmen. 1961. Colotlán. Doble Frontera contra los bárbaros. México: Universidad Nacional Autónoma de México.

Viveiros de Castro, Eduardo. 1993. "Le marbre et le myrte. De l'inconstance de l'âme sauvage". En Mémoire de la tradition, ed. A. Becquelin, A. Molinié. París: Société d'ethnologie, Université de Paris X-Nanterre.

Wagner, Roy. 2013 [1991]. "La persona fractal”. En Cosmopoliticas. Perspectivas antropológicas, ed. Montserrat Cañedo Rodríguez. Madrid: Editorial Trotta. 